引用格式: 张丽娜, 吴凤平. 基于 GSR 理论的省区初始水权量质耦合配置模型研究 [J]. 资源科学, 2017,39(3) :461-472. [Zhang L N, Wu F P. Water quantity-quality coupled modeling for initial water rights allocation among Chinese provinces on the basis of governmental strong reciprocator theory[J]. Resources Science, 2017,39(3):461-472]. DOI: 10.18402/resci.2017.03.08

\title{
基于GSR 理论的省区初始水权量质耦合配置模型研究
}

\author{
张丽娜 ${ }^{1}$, 吴凤平 ${ }^{2}$
}

(1.湖北经济学院经济与环境资源学院,武汉 430205; 2. 河海大学商学院, 南京 211100)

\begin{abstract}
摘 要: 面向最严格水资源管理制度的约束, 省区初始水权配置过程必须考虑水质对水量配置的叠加耦合制 约,同时也要考虑用水效率对水量和水质的影响。本文以政府强互惠(GSR)理论为基础,借鉴二维初始水权配置 理念, 基于耦合的视角, 结合区间数理论,利用强互惠者政府方在省区初始水权配置系统中的特殊地位和作用,通 过“奖优罚劣”的强互惠措施设计, 将水质影响叠加耦合到水量配置, 构建基于 GSR 理论的省区初始水权量质耦合 配置模型。以太湖流域为例进行案例分析, 获得不同约束情景和减排情形下的 2020 年太湖流域 9 种省区初始水权 量质耦合配置方案,研究结果表明: (1)在相同用水效率约束情景下,在受到减排情形 $h=1,2,3$ 的影响时, 江苏省和上 海市的初始水权配置区间量随着减排责任的减少而增加, 浙江省的配置区间量随着减排责任的减少而减少; (2)与 仅考虑水量或用水效率约束的省区初始水量权的配置结果相比,将水质耦合到水量配置的影响是江苏省和上海市 的初始水权配置区间量的折减, 浙江省配置区间量的增加, 以奖励浙江省的减排行为, 同时, 分情景分情形以区间 数的形式给出省区初始水权量质耦合配置结果, 更适应最严格水资源管理制度的要求。
\end{abstract}

关键词:耦合;政府强互惠; 省区初始水权;水质; 最严格水资源管理制度; 太湖流域

DOI: $10.18402 /$ resci.2017.03.08

\section{1 引言}

在全球气候变化和人类活动的双重影响下,水 资源短缺、水环境恶化和水生态退化等日益复杂的 水问题已成为困扰全球的共同挑战。Milly 等在 《Science》发表论文《Stationarity is Dead: Whither Water Management? ?指出: 适应性管理是解决水问 题的关键 ${ }^{[1]}$ 。中国水资源区域短缺严重、水体污染 严重等水问题尤为严峻,已经成为制约中国经济社 会发展的主要瓶颈 ${ }^{[2,3]}$ 。为解决中国日益复杂的水 问题, 中国实行最严格水资源管理制度,并确立了 “三条红线”, 即水资源开发利用控制红线、用水效 率控制红线和水功能区限制纳污红线 ${ }^{[4]}$ 。面向实行 最严格的水资源管理制度的要求, 协调人水矛盾、 人人矛盾的关键是准确处理好用水总量控制、用水 质量控制、用水效率控制等问题。

省区初始水权配置是政府主导下的水资源配
置模式, 是实现水权交易、发挥市场在资源配置中 起决定性作用的重要前提。明晰省区初始水权是 落实最严格水资源管理制度的重要途径,省区初始 水权配置必须尽快适应这一制度要求。省区初始 水权配置方法如何适应这一制度要求, 如何从根本 上缓解当前的水资源严峻形势, 统筹考虑水量 (量) 和水质 (质), 实现水资源高效配置, 是一个值得研 究的重要课题。

目前, 从水权配置方法的发展趋势看,已逐步 实现从比较单一配置原则向多种配置原则协商、平 衡、交互等蕴含耦合思想的方向发展。在国内,省 区初始水权 (水量权)配置又被称为“面向区域的流 域初始水权配置”或“流域初始水权第一层次配置” ${ }^{[5]}$ 蕴含耦合思想的配置方法的主要研究成果如下: (1) 基于协调的配置方法。王宗志等提出以和谐度最 大为目标的流域初始二维水权配置模型 ${ }^{[6]}$ 。肖淳等

收稿日期: 2016-10-30; 修订日期: 2017-01-09

基金项目: 国家自然科学基金项目(41271537)。

作者简介: 张丽娜, 女, 河南商丘人,博士, 讲师, 主要从事水资源管理和有效配置研究。E-mail : linazhangv@163.com 
提出以初始水权配置系统友好度函数最大为目标 的配置模型 ${ }^{[7]}$ 。(2)基于平衡的配置方法。王浩等通 过 “三次平衡”实现在统一配置系统层面的供需平 衡分析 ${ }^{[8]}$ 。张丽娜等分用水效率控制约束情景研究 用水总量控制下的省区初始水量权差别化配置模 型 ${ }^{[9]}$ 。(3)基于交互的配置方法。吴丹等构建流域初 始二维水权耦合配置的双层优化模型 ${ }^{[10]}$ 。张丽娜等 提出基于耦合视角的省区初始水权配置的研究框 架 ${ }^{[11]}$ 。国外鲜见对省区初始水权配置的研究成果, 但存在流域可分配水资源量在各省区或区域进行 配置的研究, 主要研究成果如下: (1)多模型耦合方 法。Cai 等构建了集成水资源模型、经济模型与水 文模型的耦合模型 ${ }^{[12]}$ 。(2)考虑水质影响的配置方 法。Condon 等从线性优化算法模块集成的角度,构 建了耦合物理-水文-水资源管理的水资源配置模型 ${ }^{[13]}$ 。 Kerachian、Bazargan-Lari 等先后提出了两种冲突博 弯模型,解决考虑水质影响的地表水和地下水综合 配置问题 ${ }^{[14,15]}$ 。Zhang 等系统考虑水资源配置因素、 水循环过程和污染物迁移,建立流域水量水质耦合 配置模型 ${ }^{[16]}$ 。(3)多方参与的配置方法。Read 等提 出可模拟利益相关者谈判过程的经济学权力指数 配置方法 ${ }^{\left[{ }^{17]}\right.}$ 。Wang、Hipel 等提出并应用两阶段协 作水资源配置模型 ${ }^{[18,19]}$ 。

现有配置理论与实践为省区初始水权配置起 到良好的指引作用。但面向适应最严格水资源管 理制度的要求,一方面尚缺乏对水量、水质、效率等 核心要素的综合考虑; 另一方面尚缺乏对初始水权 配置过程中不确定性、非线性等变化特征的客观揭 示。鉴于省区初始水权配置是政府(中央政府或流 域管理机构)主导下的配置模式,政府方的信息获 取及执行能力优势可充分展现其强互惠特性, 可通 过理性的制度安排,综合考虑配置的核心要素及不 确定影响,将那些对各省区方有共享意义的利益诉 求达成共识的行为规范。其中,共享意义代表可分 配水资源量, 利益诉求代表各省区的用水需求。耦 合过程是一个适应性学习过程 ${ }^{[11]}$, 通过量质耦合使 省区初始水权的配置主体相互配合、互相适应,缓 解水环境危机，提高水权配置结果的科学性和实 用性。

针对上述问题,通过以下设计予以解决, 以政
府强互惠理论 (Governmental Strong Reciprocator, 简称 GSR ) 为基础,借鉴二维初始水权配置理念(统 一考虑水量与水质 ${ }^{[2]}$, 基于耦合的视角,结合区间 数理论,利用强互惠者政府方在省区初始水权配置 系统中的特殊地位和作用, 通过“奖优罚劣”的强互 惠措施设计,构建基于 GSR 理论的省区初始水权量 质耦合配置模型, 并以太湖流域为例进行实例 分析。

\section{2 建模基础}

\section{1 省区初始水权量质耦合配置的基本原则}

省区初始水权量质耦合配置是指以中央政府 或流域管理机构为主,省区人民政府参与的民主协 商形式为辅,基于 “奖优罚劣”的原则,将水质影响 耦合叠加到省区初始水权的水量配置。基于此, 确 定量质耦合配置原则如下:

（1）政府主导、民主协商原则。耦合配置过程 应坚持政府的主导地位。政府在维护各省区公共 用水利益、公共用水意志和公共用水权力方面具有 强制性, 可保障配置结果的公平性和可操作性 ${ }^{[20]}$; 水 资源开发、利用、节约和保护都具有很强的外部性, 耦合配置离不开政府的调控和监督。同时,耦合配 置也必须体现省区人民民主参与协商的原则, 以反 映各省区的用水意愿和主张, 提高配置结果的满 意度。

（2）“奖优罚劣”原则。各省区在享受政府配置 的初始水量权和排污权的同时,要履行保护水环境 甚至减排水污染物的义务,将水资源利用的外部性 内化到水量的配置上,对超标排污“劣省区”采取水 量折减惩罚手段,对未超标排污的“优省区”施予水 量奖励安排。

\subsection{GSR 理论及其适用性分析}

GSR 理论的发展历程、理论要点及其适用性分 析,见表 1 。

\section{3 基本假设}

面向最严格水资源管理制度的约束,考虑到省 区初始水权配置具有敏感性、复杂性和不确定性等 特点,作出如下假设：

基本假设 1 :共享意义是各省区关于水权的利 益诉求和“奖优罚劣”意义体系的复合体。流域的 行政区划分属至少两个省区,各省区的用水利益与 


\section{表 1 GSR 理论及适用性分析}

Table 1 GSR theory and its applicability analysis

类别 GSR 理论及其适用性分析

理论的提出及理论要点 20 世纪 80 年代,Santa Fe Institute 的经济学家们称将愿意出面惩罚不合作个体, 以保证社群有效治理的群体成员为 “强互惠者”。强互惠者强调合作的对等性, 积极惩罚不合作个体, 哪怕自己付出高昂的代价 ${ }^{[21]}$ 。Gintis指出强互惠 者积极惩罚卸责者所表现的强硬作风使合作得以维系 ${ }^{[2]}$ 。同时,一个群体中只要存在一小部分的强互惠主义者,就 足以保持群体内大部分是利已的和小部分是利他的两种策略的演化均衡稳定。在此基础上,王覃刚指出 GSR 理论 要点是政府型强互惠者可通过制度的理性设计,利用合法性权力对卸责者给予有效的强制惩罚, 以维持合作秩序 和体现群体对共享意义的诉求 ${ }^{[23]}$ 。

在水资源管理中的应用 王慧敏等、牛文娟等首次将GSR 理论应用在水资源管理中,设计基于 GSR 理论的漳河流域跨界水资源冲突水量协 调方案 ${ }^{[24,25]}$ 。

适用性分析

根据 “奖优罚劣” 原则, 应对超标排污的不合作省区以减少水量权的方式进行利他惩罚, 对未超标排污的合作省区
以增加水量权的方式进行奖赏, 而GSR 理论指出政府方对不合作省区方给予强制惩罚, 对合作的省区方设计强互
惠措施, 表达了对违反水污染物人河湖总量控制制度的行为的纠正和对合作秩序的维持, 政府方的行为能力及合
法性优势使得其强互惠特性得以充分展现, 正因为这样的强互惠者政府方的固定存在, 那些被共同认知到的对于
初始水权配置具有共享意义的合作与利他等规范才能被制度化, 进而实现水资源的高效配置。

意义体系趋于多元化, 因而共享意义不是单一的构 成，而是各省区关于水权的利益诉求和 “奖优罚劣” 意义体系的复合体。

基本假设 2 : 各省区对共享意义体系的理解具 有差异性。作为有限理性的流域内各省区, 都是根 据自身对信息的依赖追求用水利益的最大化,选择 利已的用水策略, 导致各省区对水权的利益诉求和 “奖优罚劣”意义体系产生不同的理解。

\section{3 基于 GSR 理论的省区初始水权量质 耦合配置模型的构建}

政府强互惠者配置省区初始水权的制度安排 (IA), 就是中央政府或流域管理机构通过一个设计 $(g)$, 包括各省区对可配置水量的差别化共享规则 的设计及基于 “奖优罚劣”原则的强互惠制度设计， 统筹协调用水总量控制制度和水功能区限制纳污 制度, 嵌人用水效率控制约束, 将水质影响耦合叠 加到水量配置, 获得省区初始水权量质耦合配置方 案。其中, 将量质配置省区初始水权的共识(共享 意义, Comsign) 进行规范化的过程, 记为 $I A=g$ (Comsign)。在本文中, 用水效率控制约束情景 $S_{r}$ 与减排情形 $h$ 的具体解释 ${ }^{[9,26]}$ 见表 2 。

\section{1 各省区对可配置水量的差别化共享规则的设计}

设 $t$ 规划年政府方设计的体现省区初始水权量 质耦合配置共识的初步制度安排为 $I A_{t}=g_{t}($ Comsign $)$, 该制度安排应充分体察每一个 $i$ 省区在 $t$ 规划年对
水权的利益诉求 $\left(I n t_{i t}\right)$ ，按比例系数 $\lambda_{i t}$ 将可分配水 资源量 $W_{t}^{P_{0}}$ 配置给各省区, $P_{0}$ 表示可分配水资源量 的固定值,表示为:

$$
I A_{t}=g_{\iota}(\text { Comsign })=\sum_{i=1}^{m} \operatorname{Int}_{i t}=\sum_{i=1}^{m} \lambda_{i} W_{t}^{P_{0}}
$$

$t$ 规划年 $\lambda_{i t}$ 比例系数的确定是一项复杂的系 统工程,需兼顾制度上的敏感性、技术上的复杂性 以及省区的差异性。由于利用多情景约束下省区 初始水量权差别化配置模型 ${ }^{[9]}$, 可计算获得分情景 以区间数形式表示的流域内各省区的水量权配置 比例区间量, 该配置结果可反映用水效率控制约束 的强弱,处理配置过程中存在的各种不确定信息， 同时,用区间数表示配置比例可更好的表达各省区 对水量权的利益诉求和共享意义。

需要注意的是, 与文献[9]中的可配置水量的确 定不同之处在于,本文是基于生活饮用水、生态用 水优先保障原则, 确定可分配水资源量 (扣除各省 区生活饮用水、生态环境用水权总量）。其中,采用 生活饮用水定额法确定省区生活饮用水权,采用生 态环境用水分类计算组合法确定省区生态用水 权 ${ }^{[8]}$ 。基于此, 本文利用差别化配置模型确定省区 初始水量权配置比例区间, 记为 $\widetilde{\omega}_{i t_{r}}^{ \pm}$。结合以上分 析, 在用水效率控制约束情景 $s_{r}$ 下, $t$ 规划年强互惠 政府设计的体现省区用水利益诉求的初步制度安 排公式(1)可变形为: 


\section{表 2 用水效率控制约束情景与减排情形的解释}

Table 2 The connotation of scenarios of water-use efficiency control and emission reductions

\begin{tabular}{|c|c|}
\hline 不同约束情景与减排情形 & 具体解释 \\
\hline 用水效率弱控制约束情景 $s_{1}($ WECS1) & $\begin{array}{l}\text { 分阶段接近世界先进水平, 用水效率控制约束情景表征指标均以 } \alpha \text { 的浮动接近相关规 } \\
\text { 划设置的用水效率最低控制目标, 即 }\left[\left(x_{i j}^{-}\right)_{s_{1}},\left(x_{i j j}^{+}\right)_{s_{1}}\right]\end{array}$ \\
\hline 用水效率中控制约束情景 $s_{2}($ WECS2) & $\begin{array}{l}\text { 分阶段达到世界先进水平, 各指标的消减总量较 WECS1 时的下限值 }\left(x_{i j t}^{-}\right)_{s_{1}} \text { 消减 } \beta \text {, 即: } \\
{\left[\left(x_{i j t}^{-}\right)_{s_{2}},\left(x_{i j t}^{+}\right)_{s_{2}}\right]=\left[(1-\beta) \times\left(x_{i j t}^{-}\right)_{s_{1}},\left(x_{i j t}^{+}\right)_{s_{1}}\right]}\end{array}$ \\
\hline 用水效率强控制约束情景 $s_{3}($ WECS3) & $\begin{array}{l}\text { 分阶段超过世界先进水平, 各指标的消减总量较约束情景 WECS2 时的下限值 } \\
(1-\beta) \times\left(x_{i j t}^{-}\right)_{s_{1}} \text { 消减 } \eta \text {, 即: }\left[\left(x_{i j t}^{-}\right)_{s_{3}},\left(x_{i j t}^{+}\right)_{s_{3}}\right]=\left[(1-\beta) \times(1-\eta) \times\left(x_{i j t}^{-}\right)_{s_{1}},(1-\beta)\left(x_{i j t}^{-}\right)_{s_{1}}\right] \text { 。 }\end{array}$ \\
\hline 减排情形 $h=1$ & 表示规划年的年来水量较少,为较低流量,减排责任较大 \\
\hline 减排情形 $h=2$ & 表示规划年的年来水量适中,为低流量,减排责任大 \\
\hline ..... & $\cdots \cdots$ \\
\hline 减排情形 $h=H$ & 表示规划年的年来水量较多, 为较高流量, 减排责任较小 \\
\hline
\end{tabular}

注: $\alpha 、 \beta$ 和 $\eta$ 是区间 $[0,1]$ 上的消减比例参数,其数值越接近于 1 , 用水效率控制约束越强; 消减比例参数值的取值视具体流域内 各省区与国内外用水效率先进水平的差距而定, $j=j_{1}, j_{2}, j_{3}$ 表示用水效率控制约束情景的表征指标——农田灌溉亩均用水量、万元工 业增加值用水量和城镇供水管网漏失率; $i=1,2, \cdots, m, t=1,2, \cdots, T, i=1,2, \cdots, H, m 、 T 、 H$ 分别为配置省区、时间样本 点与减排情形的总数, $\left[\left(x_{i j t}^{-}\right)_{s_{1}},\left(x_{i j t}^{+}\right)_{s_{1}}\right]=\left[(1-\alpha) \cdot x_{i j t},(1+\alpha) \cdot x_{i j t}\right]$ 表示用水效率控制约束情景的表征指标 $j$ 在约束情景 $s_{1}$ 下的指标值; $x_{i j t}$ 为用 水效率控制约束情景的表征指标 $j$ 的最低控制目标值。

$$
\begin{aligned}
I A_{t s_{r}} & =g_{t_{r}}(\text { Comsign }) \\
& =\sum_{i=1}^{m}\left[\widetilde{\omega}_{i t s_{r}}^{-} \times W_{t}^{P_{0}}, \widetilde{\omega}_{i t s_{r}}^{+} \times W_{t}^{P_{0}}\right]
\end{aligned}
$$

\section{2 基于“奖优罚劣”原则的强互惠制度设计}

3.2.1 针对超标排污“劣省区”设计水量折减惩罚手段

（1）水污染物的综合污染当量区间数的构造。 由于流域须严格控制的人河湖污染物并不是单一 的, 故在判别一个省区的污染物排放是否超标时, 需要综合考虑多个污染物的排放对水环境的叠加 影响。因此,本文借鉴水、大气、噪声等污染治理平 均处理费用法, 引人水污染的污染当量数的概念 ${ }^{[26]}$, 核算流域人河湖主要污染物的综合污染当量数, 度 量其对流域水环境的综合影响。

水污染当量值是以 $1 \mathrm{~kg}$ 水中主要污染物 COD 为一个基准污染当量, 再按照其他水污染物的有害 程度、对生物体的毒性以及处理的相关费用等进行 测算, 并与 COD 进行比较。一般水污染物 $d$ 的污染 当量数的计算公式 ${ }^{[27]}$ 为:

$$
\begin{aligned}
& \text { 水污染物 } d \text { 的污染当量数 }\left(W P U_{d}\right) \\
& =\frac{\text { 水污染物 } d \text { 的排放量 }\left(W P_{d}\right)}{\text { 水污染物 } d \text { 的污染当量值 }\left(W P V_{d}\right)}
\end{aligned}
$$

式中一般水污染物污染当量值的量化值, 见《污水 综合排放标准》 $(\mathrm{GB} 8978-2002)^{[28]}, d=1,2, \cdots, D, D$
为水污染物类别的总数。

(2) 水量折减惩罚系数函数的构造。借鉴将流 域内区域超标排污量反映到水量配置折减上的“超 标排污惩罚系数函数” 的构造方法 ${ }^{[2]}$, 利用张兴芳等 提出的心态指标在二元区间数上的推广成果 ${ }^{[29,30]}$, 描述强互惠政府对超标排污“劣省区”采用惩罚手 段的心态, 构建单调递减的水量折减惩罚系数区间 函数 $\phi\left(v^{ \pm}\right)=\frac{2}{\pi} \arctan \left(v^{ \pm}\right)$, 定义域为 $v^{ \pm} \in R \times R, R$ 为实 数集, 值域为 $\phi\left(v^{ \pm}\right) \in[0,1] \times[0,1]$, 若 $v^{ \pm} \in(0,+\infty] \times(0$, $+\infty]$, 则 $\phi\left(v^{ \pm}\right) \in(0,1] \times(0,1]$; 若 $v^{ \pm} \notin(0,+\infty] \times(0,+\infty]$, 则 $\phi\left(v^{ \pm}\right)=[0,0]$ 。在减排情形 $h$ 下, $t$ 规划年 $i$ 省区的 水量折减综合惩罚系数函数可描述为:

$$
\left\{\begin{array}{l}
f_{\eta_{i h t}^{ \pm}}(\zeta)=E_{\eta_{i h t}^{ \pm}}+(2 \zeta-1) W_{\eta_{i h t}^{ \pm}} \\
\eta_{i h t}^{ \pm}=\sum_{k=1}^{K} \sigma_{k} \times k_{i h t k}^{ \pm} \\
k_{i h t k}^{ \pm}=1-\phi\left(W P U_{i t h}^{ \pm} / W P U_{i t k}^{ \pm}\right) \\
i=1,2, \cdots, m ; \quad t=1,2, \cdots, T ; \\
h=1,2, \cdots, H ; \quad k=1,2, \cdots, K
\end{array}\right.
$$

其中:

(1) $\eta_{i h t}^{ \pm}$为减排情形 $h$ 下 $t$ 规划年 $i$ 省区的水量综 合折减区间数; $f_{\eta_{i h t}^{ \pm}}\{0,1] \rightarrow\left[\eta_{i h t}^{-}, \eta_{i h t}^{+}\right]$是定义域 $[0,1]$ 上 的水量折减惩罚系数函数, $\zeta \in[0,1]$ 表示决策者的 
心态指标, $E_{\eta_{i t h}^{ \pm}}=\left(\eta_{i h t}^{-}+\eta_{i h t}^{+}\right) / 2$ 为 $\eta_{i h t}^{ \pm}$的期望值, $W_{\eta_{i h t}^{ \pm}}=\left(\eta_{i h t}^{+}-\eta_{i h t}^{-}\right) / 2$ 为 $\eta_{i h t}^{+}$的宽度; 当决策者的心态指 标 $\zeta=0$ 时, $f_{\eta_{i j t}^{ \pm}}(\zeta)=\eta_{i h t}^{-}$, 则称 $\zeta$ 为下限指标, 表示强 互惠政府在设计水量折减惩罚手段时持悲观心态， 即强互惠政府会设计苛刻的手段措施对“劣省区” 进行水量折减惩罚; 当 $\zeta=1$ 时, $f_{\eta_{i h t}^{ \pm}}(\zeta)=\eta_{i h t}^{+}$, 则称 $\zeta$ 为上限指标, 强互惠政府在设计水量折减惩罚手段 时持乐观心态, 即面向最严格水资源管理制度的约 束,强互惠政府会设计严格的手段措施对“劣省区” 进行水量折减惩罚; 当 $\zeta=0.5$ 时, $f_{\eta_{i t h}^{ \pm}}(\zeta)=E_{\eta_{i t h}^{ \pm}}$, 则称 $\zeta$ 为中限指标, 强互惠政府在设计水量折减惩罚手 段时持中庸心态 , 即强互惠政府会设计适中的手段 措施对“劣省区”进行水量折减惩罚。

(2)鉴于利用区间两阶段随机规划 (Inexact TwoStage Stochastic Programming, 简称ITSP)配置模式 ${ }^{[26]}$, 可分类确定不同减排情形 $h$ 下的配置方案,设利用 该方法计算获得的配置区间量为初始排污权配置 基准量, 即 $t$ 规划年 $i$ 省区关于 $d$ 污染物的初始排污 权配置区间量 $W P_{\text {idth }}^{ \pm}$。将省区内各种污染物的排放 量按污染当量值换算成污染当量数,再累加所有的 污染当量数,根据公式 (3), 得出 $t$ 规划年 $i$ 省区排放 $D$ 种污染物的总污染当量数:

$$
W P U_{i t h}^{ \pm}=\sum_{d=1}^{D} W P_{i d t h}^{ \pm} / W P V_{d}
$$

目前, 从理论研究的角度看, 可供选择的省区 初始排污权配置的比较基准主要分为两大类 ${ }^{[3]}$ : 非 经济因子配置(人口配置模式、面积配置模式、改进 现状配置模式)和经济因子配置 (排污绩效配置模 式）。设 $k=1,2,3,4$ 分别代表四种比较基准配置模 式一人口配置模式、面积配置模式、改进现状配 置模式和排污绩效配置模式。 $k_{i h t k}^{ \pm}$为对应于第 $k$ 项 比较基准的减排情形 $h$ 下 $t$ 规划年 $i$ 省区的水量折减 区间数; $\delta_{k}$ 为基于层次分析法 (Analytic Hierarchy Process, 简称 AHP $)^{[5]}$ 确定的第 $k$ 项比较基准的权 重,理由是 AHP 法是一种定性与定量相结合的实用 的权重确定方法, 尤其在处理涉及经济、社会等难 以量化的影响因素权重的确定方面,具有不可替代 的优势。

(3) $\phi\left(v^{ \pm}\right)$为超标排污水量折减惩罚系数函数;
$W P U_{i t h}^{ \pm}$为减排情形 $h$ 下 $t$ 规划年 $i$ 省区的污染物的综 合污染当量区间数; $W P U_{i t k}^{ \pm}$为基于第 $k$ 项比较基准 $t$ 规划年 $i$ 省区所配置的污染物的综合污染当量区间 数, 结合公式(3), 可知 $W P U_{i t k}^{ \pm}=\sum_{d=1}^{D} W P_{i d t k}^{ \pm} / W P V_{d}$, 其 中, $W P U_{i t k}^{ \pm}$为基于第 $k$ 项比较基准配置量; $W P_{i d t k}^{ \pm}$为 水污染物 $d$ 的污染当量值。

(3)水量折减惩罚手段的设计。强互惠政府对 于水量折减惩罚手段的设计,分以下两种情形：

(1)若 $f_{\eta_{i t h}^{ \pm}}(\zeta) \in[0,1)$, 该省区被称为超标排污的 “劣省区”, 则强互惠政府将以乘于系数 $f_{\eta_{i, \mu}^{ \pm}}(\zeta)$ 的方 式,对用水效率控制约束情景 $s_{r}(r=1,2,3)$ 下, $t$ 规 划年 $i$ 省区已获得的初始水量权进行折减。

(2)若 $f_{\eta_{i \mu}^{ \pm}}(\zeta)=1$, 该省区被称为未超标排污的 “优省区”,则强互惠政府不需对 $i$ 省区已获得的初 始水量权进行折减, 应该对其以增加水量的方式进 行奖励。基于 “奖优罚劣” 原则配置省区初始水权 的共享意义进行规范化的过程,公式(2) 可进一步 表述为:

$$
\begin{aligned}
I A_{t h s_{r}}= & \sum_{i=1}^{m}\left(\left(W_{i t t_{r}}^{ \pm}\right)_{\text {折减后 }}+\left(W_{i t s_{r}}^{ \pm}\right)_{\text {折减量 }}\right) \\
= & \sum_{i=1}^{m}\left(f_{\eta_{i t h}^{ \pm}}(\zeta) \cdot \widetilde{\omega}_{i t s_{r}}^{ \pm} \cdot W_{t}^{P_{0}}\right. \\
& \left.+\left(1-f_{\eta_{i t h}^{ \pm}}(\zeta)\right) \cdot \widetilde{\omega}_{i t s_{r}}^{ \pm} \cdot W_{t}^{P_{0}}\right)
\end{aligned}
$$

3.2.2 针对未超标排污的“优省区”设计水量奖励的 强互惠措施

将流域内各个省区进行重新排序, 不妨设 “优 省区”的集合为 $\mathrm{L}=\left\{L_{1}, L_{2}, \cdots, L_{l_{1}}\right\}$ ，“劣省区”的集合 为 $\widetilde{\mathbf{L}}=\left\{L_{l_{1}+1}, L_{l_{1}+2}, \cdots, L_{m}\right\}$ 。强互惠政府设计施予水 量奖励安排的强互惠措施, 即强互惠政府确定水量 奖励比例系数 $\theta$, 获得流域总折减水量 $\left(I A_{t h s_{r}}\right)_{\text {总折减量 }}$ $=\sum_{i=l_{1}+1}^{m}\left(W_{i t_{r}}^{ \pm}\right)_{\text {折减量 }}=\sum_{i=l_{1}+1}^{m}\left(1-f_{\eta_{i t u}^{ \pm}}(\zeta)\right) \times \widetilde{\omega}_{i t s_{r}}^{ \pm} \times W_{t}^{P_{0}}$, 以水量 奖励的方式配置给各个“优省区”的过程, 其中, $0 \leqslant \theta \leqslant 1$ 。该值的大小取决于强互惠政府鼓励水污 染物减排和开展水环境保护的态度, $\theta$ 越接近于 1 , 表明强互惠政府的态度越积极; $\theta$ 越接近于 0 , 表明 强互惠政府的态度越消极。分以下两种情形予以 
确定：

(1)强互惠政府完全依靠其强互惠优势, 确定 将 $\left(I A_{t h s_{r}}\right)_{\text {总折诚量 }}$ 奖励分配给各个 “优省区”的比例向 量 $\theta=\left(\theta_{1}, \theta_{2}, \cdots, \theta_{l_{1}}\right), \sum_{i=1}^{l_{1}} \theta_{i}=1,0 \leqslant \theta_{i} \leqslant 1$ 。由于量 质耦合配置秉守政府主导、民主协商原则, 故对此 情形不做深人探讨。

(2)强互惠政府在依靠其强互惠优势的同时， 尊重各个省区的建议,即中央政府或流域管理机 构, 与各省区进行群体协商,共同参与协商制定水 量奖励措施, 以体现各省区的用水意愿和主张,实 现民主参与。根据政府主导、民主协商的配置原 则, 确定将 $\left(I A_{t h s_{r}}\right)_{\text {总折诚量 }}$ 奖励分配给各个“优省区”的 比例向量, 不妨也设为 $\theta=\left(\theta_{1}, \theta_{2}, \cdots, \theta_{l_{1}}\right), \sum_{i=1}^{l_{1}} \theta_{i}=1$, $0 \leqslant \theta_{i} \leqslant 1$ 。在此情形下, 公式 (5)可变形为:

$$
\begin{aligned}
I A_{t h s_{r}}= & \sum_{i=1}^{l_{1}}\left(\widetilde{\omega}_{i t s_{r}}^{ \pm} \times W_{t}^{P_{0}}+\theta_{i} \times\left(I A_{t h s_{r}}\right)_{\text {总折减量 }}\right) \\
& +\sum_{i=l_{1}+1}^{m} f_{\eta_{i t h}^{ \pm}}(\zeta) \times \widetilde{\omega}_{i t s_{r}}^{ \pm} \times W_{t}^{P_{0}}
\end{aligned}
$$

\section{3 省区初始水权量质耦合配置模型的构造}

综上可知,通过一个制度安排 $(I A)$ 耦合省区初 始水量权与省区初始排污权的配置结果, 即将用水 效率控制约束情景 $s_{r}$ 下的水量权配置方案 $P_{r}$, 及 减排情形 $h$ 下的排污权配置方案 $Q_{h}$, 耦合为减排情 形 $h$ 下和用水效率控制约束情景 $s_{r}$ 下省区初始水权 量质耦合配置方案 $P Q_{r h}$ 。综上分析, $t$ 规划年流域 内各省区的初始水权量质耦合配置区间量的计算 见公式 (7)。基于区间优化思想将公式 (7)转化为 目标上、下限值子模型, 并通过 Matlab7.0 软件的 GA 求解器予以求解 ${ }^{[32]}$ 。

$$
\begin{aligned}
& W_{t h s_{r}}^{ \pm}=\left(W_{1 t h s_{r}}^{ \pm}, W_{2 h s_{r}}^{ \pm}, \cdots, W_{l_{1} t h r_{r}}^{ \pm}, W_{\left.l_{1}+1\right) t h s_{r}}^{ \pm}, \cdots, W_{m t h s_{r}}^{ \pm}\right) \\
& \text {s.t. }\left\{\begin{array}{c}
W_{i t h s_{r}}^{ \pm}=\widetilde{\omega}_{i t s_{r}}^{ \pm} \times W_{t}^{P_{0}}+\theta_{i} \times\left(I A_{t h s_{r}}\right)_{\text {总折城量 }}+W_{i t}^{L}+W_{i t}^{E} \\
\quad i=1,2, \cdots, l_{1} \\
W_{i t h s_{r}}^{ \pm}=f_{\eta_{i t h}^{ \pm}}(\zeta) \times \widetilde{\omega}_{i t s_{r}}^{ \pm} \times W_{t}^{P_{0}}+W_{i t}^{L}+W_{i t}^{E} \\
i=l_{1}+1, l_{1}+2, \cdots, m \\
h=1,2, \cdots, H ; \quad t=1,2, \cdots, T ; \quad r=1,2,3 .
\end{array}\right.
\end{aligned}
$$

式中 $W_{t h s_{r}}^{ \pm}$为减排情形 $h$ 和用水效率控制约束情景 $s_{r}$
下 $t$ 规划年量质耦合配置区间向量; $W_{i h s_{r}}^{ \pm}, i=1,2$, $\cdots, l_{1}$ 为未超标排污的 “优省区” 的量质耦合配置区 间量 $\left(\right.$ 亿 $\left.\mathrm{m}^{3}\right) ; W_{\text {iths }}^{ \pm}, i=l_{1}+1, l_{1}+2, \cdots, m$ 为超标排污 的 “劣省区”的量质耦合配置区间量 $\left(\right.$ 亿 $\left.\mathrm{m}^{3}\right)$; $\widetilde{\omega}_{i t s_{r}}^{ \pm} \times W_{t}^{P_{0}}$ 为 $i$ 省区初始水量权配置区间量 $\left(\right.$ 亿 $\left.\mathrm{m}^{3}\right)$; $\theta_{i}$ 为将流域总折减水量 $\left(I A_{t h s_{r}}\right)_{\text {总折减量 }}$ 奖励配置给各个 “优省区”的比例系数, $\sum_{i=1}^{l_{1}} \theta_{i}=1,0 \leqslant \theta_{i} \leqslant 1 ; f_{\eta_{i \mu h}^{ \pm}}(\zeta)$ 为 $i$ 省区水量折减惩罚系数函数值; $W_{i t}^{L}$ 为 $i$ 省区的 生活饮用水初始水权 $\left(\right.$ 亿 $\left.\mathrm{m}^{3}\right) ; W_{i t}^{E}$ 为 $i$ 省区的河道外 生态初始水权 $\left(\right.$ 亿 $\left.\mathrm{m}^{3}\right)$ 。

\section{4 实例分析}

\section{1 数据的收集与处理}

太湖流域在中国七大流域中水资源相对丰富, 但面向承载上海、江苏、浙江等经济较发达区域经 济社会发展的用水需求,流域的水资源和水环境承 载力表现出严重不足。面向最严格水资源管理制 度的要求, 太湖流域迫切需要加强水资源权属管 理, 做好省区初始水权配置工作。根据太湖流域水 资源条件和《太湖流域综合规划(2012-2030)》(简称 《规划》 $)^{[33]}$ 的相关成果, 针对 $75 \%$ 来水频率条件下, 核定规划年 2020 年流域河道外取水许可总量控制 指标为 339.9 亿 $\mathrm{m}^{3}$ (包括各省区直接引江水量)。本 文主要通过《太湖流域及东南诸河水资源公报 (2003-2012)》、《中国水资源公报 (2000-2012)》以及 调研等方式获取历年数据, 通过《规划》、《太湖流域 水量分配方案研究技术报告 (2012)》等 ${ }^{[3-38]}$ 获取 2020 年的预测数据。省区初始水量权差别化配置 指标值, 见表 3 。

\section{2 计算太湖流域各省区初始水权量质耦合配置区 间量}

4.2.1 各省区对可配置水量的差别化共享规则的设计

(1)优先确定各省区的生活饮用水和生态用水 的初始水权。计算步骤如下: (1)按照城镇生活用水 定额,计算确定 2020 年江苏省、浙江省和上海市的 基本生活需水量分别为 17.4 亿 $\mathrm{m}^{3} 、 10.0$ 亿 $\mathrm{m}^{3}$ 和 22.3 亿 $\mathrm{m}^{3}$ 。(2)结合《规划》预测成果 ${ }^{[33]}$, 确定 2020 年各省 区的河道外生态环境用水需求量分别为 0.9 亿 $\mathrm{m}^{3}$, 0.3 亿 $\mathrm{m}^{3}$ 和 1.0 亿 $\mathrm{m}^{3}$ 。(3)确定 2020 年可分配水资源 
表 3 省区初始水量权差别化配置指标值

Table 3 Index values of initial water rights differentiated allocation among provinces

\begin{tabular}{lrrrr}
\hline \multicolumn{1}{c}{ 配置指标 } & 江苏省 & 浙江省 & 上海市 & 统计年份 \\
\hline 现状用水量 $/$ 亿 $\mathrm{m}^{3}$ & 188.20 & 51.40 & 109.70 & 2012 年 \\
人均用水量 $/ \mathrm{m}^{3}$ & 767.13 & 441.18 & 477.79 & 2012 年 \\
亩均用水量 $/ \mathrm{m}^{3}$ & 97.02 & 42.05 & 211.86 & 2012 年 \\
人口数量 $/$ 万人 & 2453.31 & 1165.07 & 2296.01 & 2012 年 \\
区域面积 $/ \mathrm{km}^{2}$ & 19399.00 & 12093.00 & 5178.00 & 2012 年 \\
多年平均径流量 $/$ 亿 $\mathrm{m}^{3}$ & 66.00 & 72.80 & 20.10 & $2000-2012$ 年 \\
多年平均供水量 $/$ 亿 $\mathrm{m}^{3}$ & 164.57 & 59.40 & 112.10 & $2000-2012$ 年 \\
人均需水量 $/ \mathrm{m}^{3}$ & 778.00 & 612.00 & 668.00 & 2020 年 \\
万元 $\mathrm{GDP}$ 需水量 $/ \mathrm{m}^{3}$ & 66.00 & 69.00 & 48.00 & 2020 年 \\
\hline
\end{tabular}

量。即扣除太湖流域各省区生活饮用水、生态环境 用水权后的水资源总量 $W_{1}^{P_{0}}=286.75$ 亿 $\mathrm{m}^{3}$ 。

(2)利用差别化配置模型 ${ }^{[9]}$,通过 Matlab7.0 软 件的 GA 求解器予以求解 ${ }^{[32]}$ 得, 用水效率控制约束 情景下太湖流域各省区的初始水量权配置比例区 间数及配置结果, 见表 4 。结合各省区配置比例区 间数,根据公式(1)和公式(2),初步安排确定太湖 流域各省区的初始水量权共享规则。

\subsection{2 基于“奖优罚劣”原则的强互惠制度设计}

按照人口配置模式、面积配置模式、改进现状 配置模式、排污绩效配置模式和 ITSP 配置模式,依 次获得 2020 年各省区关于水污染物 COD、 $\mathrm{NH}_{3}-\mathrm{N}$ 和
$\mathrm{TP}$ 的初始排污权配置区间量。参照《污水综合排放

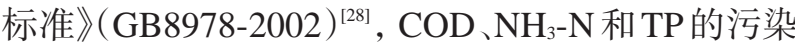
当量值分别为 $1.00 \mathrm{~kg}, 0.80 \mathrm{~kg}$ 和 $0.25 \mathrm{~kg}$, 根据一般污 染物计算公式 (3) , 计算 $\mathrm{COD} 、 \mathrm{NH}_{3}-\mathrm{N}$ 和 TP 的污染 当量数,分别累加得各省区的水污染物综合污染当 量数,见表 5 。

结合表 5 中的数据,鉴于太湖流域管理机构严 格控制污染物入河湖排放量的态度,综合考虑专家 意见,取决策者的心态指标 $\zeta=1$ 。基于 AHP法确定 表 5 中人口配置模式、面积配置模式、改进现状配置 模式和排污绩效配置模式的权重分别为 $0.30,0.19$, 0.20 和 0.31 ,根据公式 (4),计算减排情形 $h=1$ 时, 江

\section{表 4 不同情景下 2020 年太湖流域省区初始水量权配置结果}

Table 4 Results of provincial initial water rights allocation of Taihu Basin under different scenarios in 2020

\begin{tabular}{|c|c|c|c|c|c|c|}
\hline \multirow{2}{*}{ 行政分区 } & \multicolumn{2}{|c|}{ WECS1 } & \multicolumn{2}{|c|}{ WECS2 } & \multicolumn{2}{|c|}{ WECS3 } \\
\hline & 配置比例/\% & 配置结果/亿 $\mathrm{m}^{3}$ & 配置比例/\% & 配置结果/亿 $\mathrm{m}^{3}$ & 配置比例/\% & 配置结果/亿 $\mathrm{m}^{3}$ \\
\hline 江苏省 & {$[49.04,50.82]$} & {$[158.93,164.02]$} & {$[47.77,49.53]$} & {$[155.27,160.33]$} & {$[47.52,51.34]$} & {$[154.57,165.51]$} \\
\hline 浙江省 & {$[10.97,11.99]$} & {$[41.75,44.68]$} & {$[7.71,8.74]$} & {$[32.42,35.37]$} & {$[8.21,10.94]$} & {$[33.85,41.66]$} \\
\hline 上海市 & {$[37.74,39.47]$} & {$[131.51,136.47]$} & {$[42.28,43.99]$} & {$[144.53,149.45]$} & {$[39.24,42.88]$} & {$[135.81,146.27]$} \\
\hline
\end{tabular}

表 5 不同配置模式下的 2020 年太湖流域省区初始排污权的综合污染当量数

Table 5 The equivalent number of integrated pollution of provincial initial emission rights allocation of Taihu Basin under different allocation modes in 2020

$(\mathrm{kg})$

\begin{tabular}{lcrrr}
\hline 项目 & 江苏省 & \multicolumn{1}{c}{ 浙江省 } & 上海市 \\
\hline 人口配置模式 & {$[167094.05,185593.76]$} & {$[124603.50,138398.90]$} & {$[168955.64,187661.46]$} \\
面积配置模式 & {$[243692.70,270672.98]$} & {$[151913.80,168732.84]$} & {$[65046.69,72248.30]$} \\
改进现状配置模式 & {$[167653.14,186123.25]$} & {$[168614.69,187$ 156.16] } & {$[124385.36,138374.70]$} \\
排污绩效配置模式 & {$[171098.40,217407.56]$} & {$[28971.86,41390.25]$} & {$[232066.77,285146.08]$} \\
减排情形 $h=1$ & {$[183706.43,229111.29]$} & {$[129310.95,130791.23]$} & {$[149579.82,150917.49]$} \\
减排情形 $h=2$ & {$[183517.35,229265.25]$} & {$[128814.43,130864.50]$} & {$[150195.83,151062.14]$} \\
减排情形 $h=3$ & {$[182606.43,229212.50]$} & {$[128666.28,130901.63]$} & {$[149589.59,151312.51]$} \\
\hline
\end{tabular}


苏省、浙江省和上海市的超排惩罚系数分别为 $0.8564,1$, 和 0.8340 。同理,可计算当 $h=2$ 时,各省 区的超排惩罚系数分别为 $0.8563,1$ 和 0.8332 ; 当 $h=$ 3 时,各省区的超排惩罚系数分别为 $0.8560,1$ 和 0.8320 。将水质影响叠加到水量配置, 将不同情形 下的超排惩罚系数依次代人公式 (5),太湖流域管 理机构依此设计超排惩罚手段,对江苏省和上海市 的生产用水权进行折减。同时,太湖流域管理机构 对未超标排污的浙江省开展水量奖励的强互惠措 施安排,将江苏省和上海市的折减水量作为奖励, 按比例系数 $\theta$ 分配给浙江省。结合太湖流域的水 资源与水环境的发展变化状况,鉴于太湖流域管理 机构贯彻落实最严格水资源管理制度,严格控制污 染物人河湖量的决心与态度, 取 $\theta=0.95$ 。

4.2.3 太湖流域省区初始水权配置方案的比较分析

基于以上计算结果,根据公式(7), 确定不同约 束情景和减排情形下的 9 种太湖流域省区初始水权 量质耦合配置方案, 见表 6 。为了便于比较, 笔者将 9 种量质耦合配置方案与 3 种差别化配置方案和 1 种《规划》渠配置方案进行比较分析,如表6所示。

(1) 量质耦合配置方案分析。(1)从表 6 的量质 耦合配置方案可知,在同一用水效率控制约束情景 下,在受到不同减排情形的影响时,江苏省、浙江省 和上海市的配置区间量随着减排责任的减少分别 呈现递增、递减与递增的变化趋势。不妨分析在约 束情景WESC 1 下,各省区配置区间量在受到减排 情形影响时的变化规律。江苏省的配置区间量随 着减排情形 $h=1,2,3$ 的改变而增加。在受到减排情
形 $h=1,2,3$ 的影响时,江苏省的配置区间量依次为 [132.67, 137.03] 亿 $\mathrm{m}^{3} 、[132.71,137.07]$ 亿 $\mathrm{m}^{3}$ 和 $[132.72,137.08]$ 亿 $\mathrm{m}^{3}$, 呈递增趋势。浙江省的配置 区间量随着减排情形 $h=1,2,3$ 的改变而减少。即浙 江省的配置区间量依次为 [70.00, 74.19] 亿 $\mathrm{m}^{3}$ 、 $[69.88,74.06]$ 亿 $\mathrm{m}^{3}$ 和 $[69.81,73.99]$ 亿 $\mathrm{m}^{3}$, 呈递减趋 势。上海省的配置区间量随着减排情形 $h=1,2,3$ 的 改变而增加。即上海市的配置区间量依次为 [102.95，107.08] 亿 $\mathrm{m}^{3} 、[103.07,107.20]$ 亿 $\mathrm{m}^{3}$ 和 [103.15, 107.28] 亿 $\mathrm{m}^{3}$, 呈递增趋势。2 耦合配置结 果受减排情形影响而产生的变化规律的合理性分 析如下: 在减排情形 $h=1$ 时,与其他减排情形 $h=2,3$ 相比, 2020 年太湖流域在水资源来水量较少和历年 排污量较多的情形下,江苏省、浙江省和上海市存 在较大的减排压力, 同时,江苏省和上海市的超排 惩罚系数也较大, 浙江省的超排惩罚系数不变, 导 致江苏省和上海市的水量折减惩罚量较多,浙江省 因此而得到的水量奖赏量也较多。因此,与其他减 排情形 $h=2,3$ 相比, 江苏省和上海市的初始水权配 置区间量较少, 浙江省的初始水权配置区间量 较多。

(2)配置方案对比分析。(1)耦合配置方案与差 别化配置方案相比,耦合配置对各省区水权量获得 的总体影响是: 江苏省和上海市的初始水权量的折 减, 浙江省的增加。耦合配置方案可体现出强互惠 政府基于“奖优罚劣”原则的强互惠措施设计,适当 折减江苏省和上海市的初始水权量, 以奖励浙江省 的减排行为,切实控污减排,实现水资源的高效配

表 62020 年太湖流域省区初始水权配置方案

Table 6 Schemes of initial water rights allocation among provinces of Taihu Basin in 2020

\begin{tabular}{|c|c|c|c|c|c|c|}
\hline $\begin{array}{c}\text { 用水效率控制 } \\
\text { 约束情景 }\end{array}$ & $\begin{array}{l}\text { 行政 } \\
\text { 区划 }\end{array}$ & $\begin{array}{l}\text { 减排情形 } h=1 \\
\text { (减排责任大) }\end{array}$ & $\begin{array}{l}\text { 减排情形 } h=2 \\
\text { (减排责任中) }\end{array}$ & $\begin{array}{l}\text { 减排情形 } h=3 \\
\text { (减排责任小) }\end{array}$ & $\begin{array}{c}\text { 差别化配置 } \\
\text { 结果 }\end{array}$ & $\begin{array}{c}\text { 《规划》 } \\
\text { 配置结果 }\end{array}$ \\
\hline WESC1 & 江苏省 & {$[132.67,137.03]$} & {$[132.71,137.07]$} & {$[132.72,137.08]$} & {$[158.93,164.02]$} & 157.1 \\
\hline \multirow[t]{2}{*}{ （弱约束） } & 浙江省 & {$[70.00,74.19]$} & {$[69.88,74.06]$} & {$[69.81,73.99]$} & {$[41.75,44.68]$} & 58.4 \\
\hline & 上海市 & {$[102.95,107.08]$} & {$[103.07,107.20]$} & {$[103.15,107.28]$} & {$[131.51,136.47]$} & 124.0 \\
\hline \multirow{3}{*}{$\begin{array}{l}\text { WESC2 } \\
\text { (中约束) }\end{array}$} & 江苏省 & {$[135.55,137.03]$} & {$[135.59,137.07]$} & {$[135.60,137.08]$} & {$[155.27,160.33]$} & 157.1 \\
\hline & 浙江省 & {$[61.07,64.88]$} & {$[60.95,64.75]$} & {$[60.88,64.68]$} & {$[32.42,35.37]$} & 58.4 \\
\hline & 上海市 & {$[102.99,107.08]$} & {$[103.10,107.20]$} & {$[103.18,107.28]$} & {$[144.53,149.45]$} & 124.0 \\
\hline \multirow{3}{*}{$\begin{array}{c}\text { WESC3 } \\
\text { (强约束) }\end{array}$} & 江苏省 & {$[134.95,137.03]$} & {$[134.99,137.07]$} & {$[135.00,137.08]$} & {$[154.57,165.51]$} & 157.1 \\
\hline & 浙江省 & {$[61.67,71.17]$} & {$[61.55,71.04]$} & {$[61.49,70.97]$} & {$[33.85,41.66]$} & 58.4 \\
\hline & 上海市 & {$[98.38,107.08]$} & {$[98.49,107.20]$} & {$[98.56,107.28]$} & {$[135.81,146.27]$} & 124.0 \\
\hline
\end{tabular}


置。例如, 在情景WESC 1 下, 在受到减排情形 $h=1$, 2,3 的影响时,江苏省的初始水权配置区间量由 $[158.93,164.02]$ 亿 $\mathrm{m}^{3}$ 折减为 $[132.67,137.03]$ 亿 $\mathrm{m}^{3}$ 或 $[132.71,137.07]$ 亿 $\mathrm{m}^{3}$ 或 $[132.72,137.08]$ 亿 $\mathrm{m}^{3}$; 上海 市的初始水权配置区间量由 $[131.51,136.47]$ 亿 $\mathrm{m}^{3}$ 折减为 $[102.95,107.08]$ 亿 $\mathrm{m}^{3}$ 或 $[103.07,107.20]$ 亿 $\mathrm{m}^{3}$ 或 $[103.15,107.28]$ 亿 $\mathrm{m}^{3}$; 浙江省的初始水权配置区 间量由[41.75,44.68] 亿 $\mathrm{m}^{3}$ 增加为 $[70.00,74.19]$ 亿 $\mathrm{m}^{3}$ 或 $[69.88,74.06]$ 亿 $\mathrm{m}^{3}$ 或 $[69.81,73.99]$ 亿 $\mathrm{m}^{3}$ 。在情景 WESC2 和 WESC3 下, 在受到不同减排情形的影响 时,江苏省、上海市和浙江省也分别呈现折减、折减 和增加的变化趋势。(2)耦合配置方案与单一的《规 划》配置方案相比, 分不同用水效率控制约束情景 和减排情形, 以区间数的形式给出 9 种量质耦合配 置方案, 为决策者提供更为准确的决策空间, 可降 低不确定性影响所带来的水权配置决策风险, 提高 水权配置决策的效率。任意一个量质耦合配置方 案与《规划》配置方案相比, 江苏省和上海市的量质 耦合配置区间量与《规划》配置量相比较少, 浙江省 的相比较多,配置结果之间的差异也正是水质耦合 叠加影响水量配置的强互惠设计的一种表现, 促进 节水减排,更适应最严格水资源管理制度的要求。

\section{5 结论及建议}

\section{1 结论}

借鉴初始二维水权配置理念, 以 GSR 理论为基 础,结合区间数理论,根据“奖优罚劣”原则和政府 主导及民主参与原则,利用中央政府或流域管理机 构在省区初始水权量质耦合配置系统中的特殊地 位和作用,通过一个制度设计,包括省区获取水量 权的行为规则设计,以及基于“奖优罚劣”原则的强 互惠制度设计,即对超标排污“劣省区”采取水量折 减惩罚手段和对未超标排污的“优省区”施予水量 奖励的强互惠措施安排,将水质影响耦合叠加到水 量配置,构建基于 GSR 理论的省区初始水权量质耦 合配置模型。通过案例研究,获得太湖流域不同约 束情景和减排情形下的 9 种省区初始水权量质耦合 配置方案, 对其进行了合理性分析, 并与仅考虑水 量或用水效率控制的水量权配置方案进行对比分 析,分析结果表明:基于“奖优罚劣”原则的量质耦 合配置, 应当适量折减江苏省和上海市的水量, 以
奖励浙江省的减排行为, 同时, 配置结果的差异也 正是水质影响水量配置的一种表现。在相同用水 效率约束情景下,江苏省和上海市的初始水权配置 区间量随着减排责任的减少而增加,浙江省的配置 区间量随着减排责任的减少而减少。最后,在最严 格水资源管理制度框架下, 结合配置方案, 提出促 进太湖流域省区初始水权配置工作顺利开展的政 策建议。

\section{2 建议}

结合太湖流域的水资源条件和区域经济特点， 面向最严格水资源管理制度的约束,提出应用省区 初始水权量质耦合配置方法的相关政策建议。一 是建议太湖流域管理机构能与各省区代表、水权配 置专家小组协商, 结合不同用水效率约束及减排情 形,设计对超标排污的江苏省和上海市的水量惩罚 政策, 及对未超标排污的浙江省的水量奖励措施, 建立政府强互惠下的奖惩制度,制定考核办法, 考 核结果作为综合考核评估省区政府相关领导的重 要依据之一, 以保障省区初始水权量质耦合配置成 果的应用。二是建议太湖流域管理机构协调好各 个职能部门之间的关系，以促进省区初始水权配置 方案的顺利实施。三是建议太湖流域管理机构制 定相应的《太湖流域水量调度管理办法》,明确水量 调度原则、权限等内容, 使省区初始水权配置方案 的落实有章可循。

\section{参考文献 (References) :}

[1] Milly P C D, Julio B, Malin F, et al. Stationarity is dead: Whither water management?[J]. Science, 2008,319(5863):573-574.

[2] 王宗志, 胡四一, 王银堂. 流域初始水权分配及水量水质调控 [M]. 北京: 科学出版社, 2011. [Wang Z Z, Hu S Y, Wang Y T. Initial Water Right Allocation and Joint Regulation of Water Quantity and Quality in a Basin[M]. Beijing: Science Press, 2011.]

[3] 吴凤平, 贾鹏, 张丽娜. 基于格序理论的水资源配置方案综合 评价 [J]. 资源科学, 2013, 35 (11) : 2232-2238. [Wu F P, Jia P, Zhang L N. Comprehensive evaluation of water resource allocation schemes based on lattice- order theory $[\mathrm{J}]$. Resources Science, 2013,35(11):2232-2238.]

[4] 左其亭. 最严格水资源管理保障体系的构建及研究展望 $[\mathrm{J}]$. 华 北水利水电大学学报 (自然科学版), 2016,37(4): 7-11. [Zuo 
Q T. Guarantee system construction and research prospects of the strictest water resources management[J]. Journal of North China University of Water Resources and Electric Power (Natural Science Edition) ,2016,37(4):7-11.]

[5] 尹明万, 于洪民,陈一鸣, 等. 流域初始水权分配关键技术研究 与分配试点 $[\mathrm{M}]$. 北京: 中国水利水电出版社, 2012. [Yin M W, Yu H M, Chen Y M, et al. The Key Technology and Pilot Program of Initial Water Rights in a Basin[M]. Beijing: China Water Power Press , 2012.]

[6] 王宗志, 张玲玲, 王银堂, 等. 基于初始二维水权的流域水资源 调控框架初析 [J]. 水科学进展, 2012,23(4) :590-598. [Wang Z Z, Zhang L L, Wang Y T, et al. Preliminary theoretical framework of water resources operation based on initial two-dimensional water rights in a basin[J]. Advances in Water Science, $2012,23(4): 590-598$.

[7] 肖淳,邵东国,杨丰顺, 等. 基于友好度函数的流域初始水权分 配模型[J]. 农业工程学报,2012,28(12): 80-85. [Xiao C, Shao D G, Yang F S, et al. Initial water rights allocation models at river basin scale based on friendly function[J]. Transactions of the Chinese Society of Agricultural Engineering, 2012,28(12) : 80-85.]

[8] 王浩,党连文,谢新民,等. 流域初始水权分配理论与实践 $[\mathrm{M}$ ] 北京: 中国水利水电出版社, 2008. [Wang H, Dang L W, Xie X $\mathrm{M}$, et al. Theory and Practice on Allocation of Initial Water Rights in a Watershed[M]. Beijing: China Water Power Press, 2008.]

[9] 张丽娜, 吴凤平, 张陈俊. 用水效率多情景约束下省区初始水 量权差别化配置研究 $[\mathrm{J}]$. 中国人口·资源与环境, 2015,25(5) 122-130. [Zhang L N, Wu F P, Zhang C J. Research on initial water rights differentiated allocation among provinces restricted to water- use efficiency in multiple scenarios[J]. China Population, Resources and Environment, 2015, 25 (5 ) : 122-130.]

[10] 吴丹, 吴凤平. 基于双层优化模型的流域初始二维水权耦合配 置 $[\mathrm{J}]$. 中国人口·资源与环境, 2012,22(10) : 26-34. [Wu D,Wu F P. The coupling allocation of initial two-dimensional water rights in basin based on the bi- hierarchy optimal model[J]. China Population, Resources and Environment, 2012, 22 (10): 26-34.]

[11] 张丽娜, 吴凤平, 贾鹏. 基于耦合视角的流域初始水权配置框 架初析-最严格水资源管理制度约束下 [J]. 资源科学, 2014,36 (11) : 2240-2247. [ Zhang L N, Wu F P, Jia P. A preliminary theoretical framework of basin initial water rights allocation from a coupling perspective and when constrained by the strictest water resources management system $[\mathrm{J}]$. Resources Science, 2014,36(11):2240-2247.]

[12] Condon L E, Maxwell R M. Implementation of a linear optimization water allocation algorithm into a fully integrated physical hydrology model[J]. Advances in Water Resources, 2013,60(8): 135-147.

[13] Cai X, Ringler C, Rosegrant M. Modeling Water Resources Management at the Basin Level-Methodology and Application to the Maipo River Basin[R]. Washington: International Food Policy Research Institute, 2006.

[14] Bazargan-Lari M R, Kerachian R, Mansoori A. A conflict resolution model for the conjunctive use of surface and groundwater resources that considers water quality issues: A case study $[\mathrm{J}]$ Journal of Environmental Management, 2009,43(3) :470-482.

[15] Kerachian R, Fallahnia M, Bazargan-Lari M R, et al. A fuzzy game theoretic approach for groundwater resources management: Application of Rubinstein bargaining theory[J]. Resources, Conservation and Recycling , 2010, 54(10):673-682.

[16] Zhang W, Wang Y, Peng H, et al. A coupled water quantityquality model for water allocation analysis[J]. Water Resources Management, 2010,24(3):485-511.

[17] Read L, Madani K, Inanloo B. Optimality versus stability in water resource allocation[J]. Journal of Environmental Management, 2014, 133(15):343-354.

[18] Wang L, Fang L, Hipel K W. Mathematical programming approaches for modeling water rights allocation[J]. Journal of Water Resources Planning and Management, 2007, 133(1) :50-59.

[19] Wang L, Fang L, Hipel K W. Basin- Wide cooperative water resources allocation[J]. European Journal of Operational Research,2008,190(3):798-817.

[20] 李晶. 中国水权 [M]. 北京: 知识产权出版社, 2008. [Li J. China Water Rights[M]. Beijing: Intellectual Property Publishing House, 2008.]

[21] Gintis H, Bowles S, Boyd R, et al. Explaining altruistic behavior in humans[J]. Evolution and Human Behavior, 2003, 24(3) : 153172.

[22] Gintis H. Strong reciprocity and human sociality[J]. Journal of Theoretical Biology, 2000,206(2) : 169-179.

[23] 王覃刚. 制度演化:政府型强互惠模型[D]. 武汉:华中师范大 学, 2007. [Wang T G. Institutional Evolution: The Strong Reciprocity Model of Government[D]. Wuhan: Central China Normal University, 2007.

[24] 王慧敏, 于荣, 牛文娟. 基于强互惠理论的漳河流域跨界水资 源冲突水量协调方案设计 $[\mathrm{J}]$. 系统工程理论与实践, 2014,34 (8) : 2170-2178. [Wang H M, Yu R, Niu W J. Water resources allocation coordination program design of Zhanghe river basin transboundary water resources conflicts based on strong reciprocity theory[J]. Systems Engineering-Theory \& Practice, 2014,34(8):2170-2178.]

[25] 牛文娟,王伟伟,邵玲玲, 等. 政府强互惠激励下跨界流域一级 水权分散优化配置模型 $[\mathrm{J}]$. 中国人口・资源与环境, 2016,26 
(4) : 148- 157. [Niu W J, Wang W W, Shao L L, et al. The decentralized optimization allocation model of initial water rights of trans-boundary river basin under government's strong reciprocity incentive[J]. China Population, Resources and Environment , 2016,26(4) :148-157.]

[26] 张丽娜, 吴凤平, 王丹. 基于纳污能力控制的省区初始排污权 ITSP配置模型 $[J]$. 中国人口・资源与环境, 2016,26(8) : 88-96. [Zhang L N, Wu F P, Wang D. Inexact two- stage stochastic programming model of provincial initial emission rights allocation under the total emission control of water pollutants[J]. China Population, Resources and Environment, 2016, 26( 8) : 8896.]

[27] 宗良纲. 环境管理学[M]. 北京: 中国农业出版社, 2005. [Zong L G. Environmental Management Science[M]. Beijing: China Agriculture Press , 2005.]

[28] 中华人民共和国环境保护部,国家质量监督检验检疫总局. GB8978-2002 污水综合排放标准[S]. 北京: 中国环境科学出版 社, 2001. [Ministry of Environmental Protection of the People's Republic of China, General Administration of Quality Supervision, Inspection and Quarantine of the People's Republic of China. GB8978-2002 Integrated Wastewater Discharge Standard [S]. Beijing: China Environmental Science Press , 2001.]

[29] 张兴芳, 管恩瑞, 孟广武. 区间值模糊综合评判及其应用 [J]. 系 统工程理论与实践, 2001,21(12):81-84. [Zhang X F, Guan E R, Meng G W. Interval-valued fuzzy comprehensive evaluation and its application[J]. Systems Engineering-Theory \& Practice, 2001,21(12):81-84.]

[30] 胡启洲, 张卫华. 区间数理论的研究及其应用 $[\mathrm{M}]$. 北京: 科学 出版社, 2010. [Hu Q Z, Zhang W H. Interval Number Theory and Its Application[M]. Beijing: Science Press , 2010.]

[31] 于术桐,黄贤金,程绪水,等. 流域排污权初始分配模式选择 [J]. 资源科学, 2009, 31 (7) : 1175-1180. [Yu S T, Huang X J, Cheng X S, et al. Mode selection of basin initial emission permits allocation[J]. Resources Science, 2009, 31 (7) : 1175 1180.]

[32] Croux C, Filzmoser P, Oliveira M R. Algorithms for ProjectionPursuit robust principal component analysis[J]. Chemometrics and Intelligent Laboratory Systems, 2007, 87 (2) :218-225.

[33] 水利部太湖流域管理局. 太湖流域综合规划(2012-2030)[Z] 上海: 水利部太湖流域管理局, 2013. [Taihu basin Administration of Ministry of Water Resources of the People's Republic of China. Integrated Water Resource Plan of Taihu basin
2012-2030) [Z]. Shanghai: Taihu basin Administration of Ministry of Water Resources of the People's Republic of China,2013.]

[34] 水利部太湖流域管理局. 太湖流域及东南诸河水资源公报 (2003-2012) [EB/OL]. (2004-01-30) [2016-10-31]. http://www. tba.gov.cn//tba/content/TBA/lygb/szygb/index.html. [Taihu basin Administration of Ministry of Water Resources of the People' $s$ Republic of China. Water Resources Bulletin of Taihu basin and Southeast Rivers (2003-2012)[EB/OL].(2004-01-30 )[2016-1031]. http://www.tba.gov.cn//tba/content/TBA/lygb/szygb/index html.]

[35] 中华人民共和国水利部. 中国水资源公报(2000-2012)[M]. 北 京: 中国水利水电出版社, 2001-2013. [Ministry of Water Resources of People's Republic of China. China Water Resources Bulletin (2000-2012)[M]. Beijing: China Water \& Power Press, 2001-2013.]

[36] 水利部太湖流域管理局. 太湖健康状况报告(2008-2012)[EB/ OL]. (2009- 02- 20) [2016- 10- 31]. http://www.tba.gov.cn//tba/ content/TBA/lygb/thjkzkbg/index.html. [Taihu basin Administration of Ministry of Water Resources of the People' s Republic of China. The Health Status Report of Taihu basin (20082012)[EB/OL].(2009-02-20 )[2016-10-31]. http://www.tba.gov. $\mathrm{cn} / /$ tba/content/TBA/lygb/thjkzkbg/index.html. ]

[37] 太湖流域管理局水利发展研究中心, 太湖流域水文水资源监 测中心. 太湖流域水量分配方案研究技术报告 $[R]$. 上海: 水利 部太湖流域管理局, 2012. [ Development Research Center of Water Resources Institute in Taihu basin, Water Monitoring Ministry of Water Resources and Hydropower in Taihu basin The Research Report of the Water Allocation Schemes in Taihu basin[R]. Shanghai: Taihu basin Administration of Water Resources of the People's Republic of China, 2012.]

[38] 中华人民共和国国家发展和改革委员会, 中华人民共和国环 境保护部,住房和城乡建设部,等.太湖流域水环境综合治理 总体方案 (2013 年修编) [EB/OL] (2013-12-30) [2016-10-31]. http://www.sdpc.gov.cn/fzgggz/dqjj/zhdt/201401/020140114579 168375061.pdf. [National Development and Reform Commission of the People's Republic of China, Ministry of Environmental Protection of the People's Republic of China, Ministry of Housing and Urban- Rural Development, et al. Comprehensive Management Scheme of Water Environment in Taihu basin (2013 revision) [EB/OL]. (2013-12-30 ) [2016-10-31]. http:// www.sdpc.gov.cn/fzgggz/dqjj/zhdt/201401/W020140114579168 375061.pdf.] 


\title{
Water quantity-quality coupled modeling for initial water rights allocation among Chinese provinces on the basis of governmental strong reciprocator theory
}

\author{
ZHANG Lina', WU Fengping ${ }^{2}$ \\ (1. School of Economics and Environmental Resources, Hubei University of Economics, Wuhan 430205, China; \\ 2. Business School of Hohai University, Nanjing 211100, China)
}

\begin{abstract}
In accordance with constraints of the strictest water resource management system, the initial water rights allocation among Chinese provinces must embed water quality effects into the process of water allocation. The processes of water allocation also needs to take the effect of wateruse efficiency to water quantity and quality into consideration. Combining with interval number theory, governmental strong reciprocator theory and initial two-dimensional water rights allocation theory from the coupling perspective, we designed a strong reciprocator system based on the principle of 'rewarding efficiency and penalizing inefficiency' using the special position and role of the governmental strong reciprocator. As a result of the strong reciprocator system, we propose a water quantity- quality coupled model for the provincial initial water rights allocation by embedding water quality effects into the processes of water allocation. The model of provincial initial water rights allocation is applied to Taihu Basin, to get its nine schemes of the provincial initial water rights allocation in 2020 constrained by different water- use efficiency and emission patterns. At the same standards of water-use efficiency, the amount of initial water rights allocation interval in Jiangsu Province and Shanghai City increases with decreasing water emission responsibility; the amount of Zhejiang Province is otherwise. These results, compared with allocation schemes that merely consider water quantity and water- use efficiency, show that the interval quantity from Jiangsu Province and Shanghai City should be reduced, while the interval quantity from Zhejiang Province should be increased as an incentive for the reduction in water pollutants. Water quantity- quality coupled schemes of provincial initial water rights allocation manifested by interval in multiple scenarios are according with the requirement, which is constrained by the strictest water resource management system.
\end{abstract}

Key words : coupling; governmental strong reciprocator; provincial initial water rights; water quality; strictest water resources management system; Taihu Basin 